\title{
REITERATION RELATIONS IN EFL STUDENT ACADEMIC WRITING AND THE EFFECTS OF ONLINE LEARNING
}

\author{
Gabriela Hublová
}

\begin{abstract}
Lexical cohesion significantly contributes to a text's thematic progression, and by means of it to perceived coherence. Therefore, the ability to express lexical cohesive relations represents one of the areas of learners' inter-language that are to be developed in foreign language instruction. The paper reports on the development of lexical cohesion (namely the class of reiteration) in EFL undergraduate and postgraduate academic writing as a result of participation in a purely online academic writing course involving no face-toface interaction. The course was delivered at Masaryk University, Brno, Czech Republic. To determine the effect of the treatment, a quasi-experimental one-group pre-test post-test design was followed, with the genre of argumentative essay assigned for both measures. The pre/post-test analysis comprised two stages: the identification and classification of reiteration pairs based on Tanskanen's framework (2006) followed by subsequent evaluation of each pair in terms of its appropriateness/correctness. Thus, every pair was classified either as appropriate/well-formed or as displaying a sign of immature writing with respect to given genre expectations. The occurrence of key lexical items forming chains of cohesion was also monitored. After the treatment, the use of reiteration devices in students' compositions improved in several respects. A greater variety of reiteration relations was observed, with a statistically significant decline in simple repetition and corresponding increases in other categories of reiteration relations. In addition, the pre/post-test comparison showed a statistically significant increase in the number of reiteration pairs that were classified as appropriate/well-formed, and in the frequency of key lexical items.
\end{abstract}

\section{Keywords}

English as a foreign language, student academic writing, argumentative essay, lexical cohesion, reiteration, online learning, electronic feedback

\section{Introduction}

In contemporary foreign language instruction, emphasis is often placed on providing meaningful and authentic learning opportunities, learning in personalised contexts, developing learner autonomy and responsibility, and encouraging learner collaboration (for details, cf. Kumaravadivelu 2006). Besides these principles, there is another significant feature of foreign language teaching and learning and that is the use of information and communication technology (ICT). 
Generally, it is believed that ICT has a great potential to encourage learning outside the classroom and at the same time may successfully cater for those principles of foreign language instruction that are to be observed (Larsen-Freeman \& Anderson 2011: 200). Recent availability and popularity of ICT among teachers and students have resulted in designing a number of blended mode and 100 per cent online courses that are believed to develop learners' communicative competence. Nevertheless, as promising as it may appear, learning a language in a predominantly or purely online environment is substantially different from traditional classroom instruction. Therefore, this type of instruction should be subjected to thorough investigation helping to decide whether online learning leads to the expected outcomes, i.e. whether there is a positive impact on learners' communicative competence. The present study aims to contribute to this area of research, examining the potential development in the area of lexical cohesion as one of the key aspects of discourse competence.

When compared to other types of cohesion, lexical cohesion has been regarded as the most dominant type, accounting for approximately 50 per cent of all cohesive relations (Hasan 1984: 218). The significance of this type of cohesion, however, lies especially in its ability to contribute to a text's thematic progression and its organisation, as proved by Hoey (1991) or Morris and Hirst (1991). As such, lexical cohesion significantly contributes to perceived coherence and plays a key role in the processes of text production and text interpretation. In EFL student academic writing, the use of lexical cohesive devices may be regarded as an important aspect of discourse competence.

\section{Cohesion as a key feature of discourse competence}

According to the communicative paradigm, the main aim of foreign language instruction consists in developing learners' communicative competence (CC) (e.g. Savignon 1997), which is an outcome of interplay among its partial competences, such as linguistic, pragmatic, intercultural or discourse competence (cf. Canale 1983, Savignon 1983, Bachman \& Palmer 1996, Usó-Juan \& Martínez-Flor 2006, or Celce-Murcia 2007). Usó-Juan and Martínez-Flor (2006) define discourse competence as "the selection and sequencing of utterances or sentences to achieve a cohesive and coherent spoken or written text given a particular purpose and situational context" (ibid.: 17).

The relationship between the concepts of coherence and cohesion has been widely discussed in discourse studies. While it may be concluded that there is a general agreement that coherence and cohesion are two distinct notions (but not mutually exclusive), there is a considerable disagreement about what differentiates the two. Recent concepts (e.g. Hoey 1991, Tanskanen 2006) see 
cohesion, i.e. "grammatical and lexical elements on the surface of a text which can form connections between parts of the text" (Tanskanen 2006: 7), as one of the factors that may contribute to coherence, and thus signal coherence in texts. In addition, recent approaches also stress the collaborative and dialogic nature of monologic discourse/use of cohesion. Linell (1998: 267) argues that in both types of monologic discourse, spoken and written, producers produce their topics and arguments with virtual addressees in mind. Considering the use of cohesion in these terms, the producer (writer) is trying to provide such formal connections that would lead the receiver (reader) to the expected interpretation of the message that is to be conveyed, and the receiver is trying to identify these connections to arrive at an interpretation. The success or failure in one or both stages determines the success of communication.

Since the publication of Cohesion in English (Halliday \& Hasan 1976), scholars from different fields and all over the world have been focusing their attention on cohesion, studying it from various perspectives, applying numerous approaches and procedures. Cohesion has thus clearly become a subject of intensive debate taking place not only within but also outside the linguistic community. Halliday and Hasan use the term 'cohesion' to refer to relations of meaning that exist within a text and that define it as a text. According to them, cohesion occurs when the interpretation of meaning of a certain item depends on the existence and meaning decoding of another item (Halliday \& Hasan 1976: 4). Halliday and Hasan claimed that the semantic relations are realised through both grammar and vocabulary. Since the 1970s, cohesion has been conceptualised as comprising four types of grammatical cohesive ties (conjunctives, reference, substitution and ellipses) and two categories of lexical cohesion (reiteration and collocation). In addition, some authors (e.g. de Beugrande \& Dressler 1981) recognise the cohesive role of parallelism, theme-rheme articulation, and given-new information organisation, which are commonly known as structural cohesion. Brown and Yule (1983) then expanded the domain of the existence of cohesive relations beyond the text itself, claiming that cohesion stems from the potential of overt linguistic mechanisms (lexical and grammatical) to establish internal links between parts of the text as well as between the text and its context, thus serving as signals available to, but not necessarily deployed by the writer (Brown \& Yule 1983).

In terms of lexical cohesion, which stands in the centre of attention of the present study, certain discrepancy between the sub-class of reiteration and collocation may be observed: while the former is generally clearly defined as a cohesive link achieved by repetition of the same lexical item and by the use of synonyms, paraphrases, opposites and lexical items with a more general and 
a more specific meaning (Dontcheva-Navratilova 2012: 12), the latter category comprises a mixture of various lexical relations falling within much less exactly defined sub-categories.

The most influential models of lexical cohesion include Halliday and Hasan (1976), Hasan (1985), Martin (1992), Hoey (1991, 2001) and Tanskanen (2006). The linguistic analysis conducted in the present study was based on the most recent categorisation suggested by Tanskanen (2006). This model of lexical cohesion was found appropriate for several reasons. First, the individual categories are defined in such a way that mostly allows for a straightforward identification and subsequent classification of lexical relations; at the same time, the categories are general enough to include relations that could be left unnoticed when applying some of the previous classifications. Next, the categorisation was proposed for analysis of four distinct types of discourse, one of them being the written monologue (the genre of academic article). Finally, unlike some of its counterparts, Tanskanen's conceptualisation is suitable for analysis of the entire text, which was a fundamental criterion, given the aim of the present study.

\section{Methodology}

\subsection{Study aim and research questions}

The aim of the study was to decide whether the experimental treatment carried out in the Masaryk University Learning Management System and the Peer Review Application resulted in the development of lexical cohesion, specifically the class of reiteration, in EFL student academic writing. The class of collocation was not considered partly due to the persistent vagueness associated with this category and also because of its relatively lower significance compared to other aspects of discourse competence that are commonly developed as part of foreign language instruction. The main research question was stated as follows: Did the intervention result in a more effective use of lexical cohesion (subclass of reiteration) in participating students' EFL academic writing? The main research question was then operationalised in three sub-questions:

1) What types of reiteration relations were formed by the participating students before and after the treatment?

2) Was there a difference in terms of perceived appropriateness/correctness of the individual reiteration pairs before and after the treatment? If so, in what way and why?

3) Was there a difference in the length of chains of cohesion formed by key lexical units signalling thematic progression of a text? If so, in what way and why? 


\subsection{Experimental treatment}

The intervention, whose effect on the use of reiteration devices was investigated, consisted in participation in a thirteen-week 100 per cent online course of academic writing CJV_AW Academic Writing ONLINE, offered by the Masaryk University Language Centre, Brno, Czech Republic. The intervention was realised in the Masaryk University Learning Management System and the Peer Review Application and involved no face-to-face interaction between the course instructor and its participants or among the participants themselves. As regards the theory of learning and second language acquisition theory, the treatment was mostly grounded in cognitive and social constructivism (the theories were reflected e.g. in promoting active learning, learner autonomy and collaborative learning) and in the Output Hypothesis and the three functions of output, namely the noticing, hypothesis-testing and metalinguistic function, formulated and reformulated by Swain $(1985,2005)$. The approach to teaching and learning writing followed the process/genre-based approach (Badger $\&$ White 2000). Besides, common principles of the so-called student-oriented approach, such as personalised instruction, partnership between the teacher and students, and positive/motivating criticism were also carefully observed.

The course participation involved independent interaction with the study materials structured in 13 (weekly) modules (full learner autonomy), successful completion of eleven electronic quizzes (required) and contribution to five asynchronous online discussions (required) designed to encourage reflection on the learning process and student collaboration. The core of the intervention consisted in the composition of two writing in-term assignments, a comparison/ contrast essay and an argumentative essay. The assignments were constructed in compliance with the main principles of the process/genre-based approach and encouraged effective utilization of electronic teacher and peer-feedback. The peer-feedback was provided by the students participating in the course.

\subsection{Study design}

The study followed a quasi-experimental one-group pre-test post-test design (e.g. Gall, Gall \& Borg 2010: 304), which can be represented as $\mathrm{O}_{1}-\mathrm{X}-\mathrm{O}_{2}$, where $\mathrm{X}$ stands for experimental treatment, and $\mathrm{O}_{1} / \mathrm{O}_{2}$ for measurements conducted before (pre-test) and after the treatment (post-test). As much other educational/ applied linguistics research, this study also suffered from the impossibility of random assignation of participants to control and experimental groups, which clearly ruled out the application of a true experiment. 
The absence of a control group inevitably results in increased risks to the internal validity of the quasi-experiment (Cohen, Manion \& Morrison 2011: 322). To eliminate extraneous variables representing serious threats (e.g. simultaneous participation in another EFL academic writing course) and to be able to reflect upon the influence of other less serious influences that might account for the pre-test/post-test differences, a number of potential extraneous variables were investigated by means of two questionnaires administered before and after the treatment. The questionnaire items addressed the following areas: previous experience with online learning and with providing peer-review, attitude towards learning English, simultaneous enrolment on language courses plus other ways of developing English, motivation to enrol on the CJV_AW academic Writing ONLINE course, conditions experienced during the pre-test and posttest including the writer's effort, and the actual experience of participation in the given online academic writing course and the experience of providing and receiving electronic teacher-review and peer-review.

Both the pre-test and post-test were administered electronically in the researcher's presence and comprised authoritative writing tasks, namely the Writing task 2 of the IELTS Academic examination. From the variety of possible academic writing genres, an argumentative essay was selected, with emphasis on the comparability of topics assigned for the pre- and post-tests. The suggested length of writing was 250-300 words.

\subsection{Participants}

The research sample included 26 undergraduate and postgraduate students of various study programmes (humanities, science and technical disciplines) at Masaryk University, Brno, Czech Republic, who enrolled in the CJV_AW Academic Writing ONLINE course in autumn 2014 and spring 2015. The participants' entrance level of writing fell within Band 5-7 of the IELTS, or level B1+ to level B2 of the CEFR. Students doing English as their major were prevented from enrolling in the course. Only those students who expressed their agreement with research participation by means of signing an informed consent form were included in the study.

\subsection{Analytical procedure}

The analysis of the pre- and post-test corpora in terms of reiteration relations comprised several steps. The aim of the first step was to identify pairs of reiteration and classify them according to the conceptualisation proposed by Tanskanen (2006), which proved to be most suitable for the purposes of the present study. 


\section{Reiteration Relations in EFL Student Academic Writing AND THE EFFECTS OF ONLINE LEARNING}

Tanskanen's analysis of reiteration is based on three concepts: the concept of lexical unit (e.g. culture, cultural or cultural determinism), the concept of lexical pair, which is formed by two related lexical units, and the concept of lexical chain (or chain of cohesion), which is formed when more than two lexical units are related, with each subsequent unit being linked to the previous one(s). The procedure suggested by Tanskanen is based on manual identification of cohesive pairs to determine their occurrence throughout the entire piece of writing. In this type of analysis, three related items form two cohesive pairs, four related items three cohesive pairs, etc. The analysis progresses linearly; both intra-sentential and inter-sentential cohesive relations are recognised. The framework suggested by Tanskanen (2006) benefits from thorough analysis and comparison of previous models of lexical cohesion and makes use of the former classifications' strengths, recognising eight categories of reiteration. Each reiteration type is briefly described in Table 1.

\begin{tabular}{|l|l|}
\hline Reiteration category & Description \\
\hline 1 simple repetition (SR) & $\begin{array}{l}\text { item is repeated either in an identical form or with no other than } \\
\text { a simple grammatical change (e.g. singular - plural, present tense } \\
\text { - past tense) }\end{array}$ \\
\hline 2 complex repetition (CR) & $\begin{array}{l}\text { item is repeated in an identical form but serves a different } \\
\text { grammatical function, or an item is repeated in a non-identical } \\
\text { form but shares a lexical morpheme }\end{array}$ \\
\hline 3 substitution (SU) & use of substitution items, such as pronouns, one, do and so \\
\hline 4 equivalence (E) & $\begin{array}{l}\text { item is repeated in a form of synonym, paraphrase or word which } \\
\text { has the same meaning but comes from a different word class }\end{array}$ \\
\hline 5 generalisation (G) & relation between an item and a more general item \\
\hline 6 specification (SP) & relation between an item and a more specific item \\
\hline 7 co-specification (C-SP) & relation between two items which have a common general item \\
\hline 8 contrast (CT) & $\begin{array}{l}\text { relation between an item and another item which has an opposite } \\
\text { meaning }\end{array}$ \\
\hline
\end{tabular}

Table 1: Reiteration categories according to Tanskanen's model (2006)

Two remarks should be made here. Tanskanen (2006) treats substitution, a category that has been traditionally associated with grammatical cohesion, under lexical cohesion, and thus considers a recent shift towards applying a more functional approach; a potential change from the grammatical to the lexical perspective was suggested even by Halliday and Hasan (1976: 281). Second, the repetition of pronouns (traditionally classified under grammatical cohesion) is also included in the framework as Tanskanen argues that pronouns "function 
in a fashion very similar to genuine lexical repetitions" (2006: 50). The sample analysis follows below.

The goal of every government in the world should be to take care primarily of its own citizens. If politicians are not able to create an environment with growing economy, they have to be replaced by more capable deputies. At least this is the concept of every democratic state. Providing help to poorer nations should be done by volunteers. Therefore, rich countries are not to blame if they want to keep their wealth. (Student L, post-test)

The application of the procedure described above enables the identification of the following pairs of reiteration: government - its (substitution); government politicians (generalisation); politicians - they (substitution); politicians-deputies (equivalence); every - every (simple repetition); state - nation (equivalence); poorer nations - rich countries (contrast); rich countries - they (substitution); they - their (complex repetition); rich - wealth (complex repetition).

The aim of the second step of the analysis was to determine whether the identified cohesive pair was perceived as successfully contributing to the overall cohesion and coherence, or whether its use was considered inappropriate/ incorrect in the view of genre expectations associated with the genre of argumentative essay. The latter case, which attracted negative attention on the part of the reader, was regarded as a signal of immature writing. The main categories of inappropriate/incorrect use that were formulated for the given genre and identified in both pre- and post-tests include: clumsy repetition, ambiguity, vagueness, reiteration of items with inappropriate level of formality, reiteration of items with inappropriate level of personality, absence or redundancy, reiteration of semantically inappropriate item(s), and reiteration of grammatically incorrect form(s). Clearly, not all of these categories were identified for all sub-classes of reiteration. In addition, it needs to be admitted that the evaluation of some of the above categories is prone to a certain degree of subjectivity.

The categories introduced above need some more attention. Clumsy repetition or, as Hoey (1991: 243) puts it, "clumsy juxtaposition", may be regarded as a sign of immature writing skills. It typically occurs when the same lexical item is repeated in adjacent sentences or even within a single sentence. According to Hoey (1991: 243), adjacent sentences are less prone to bonding as, in English, writers and readers would usually consider such a type of repetition clumsy. Clumsy repetition mostly applies to simple repetition, but can be also identified in complex repetition, typically when the item is repeated within the same sentence. Naturally, not all cases of repetition of the same item in adjacent 
sentences or within a single sentence are regarded as instances of clumsiness, the expected consistency in the use of key terminology in academic writing being an apt example. Ambiguity concerns the use of pronouns which generally needs to be accomplished with care, as this type of cohesion is naturally prone to forming ambiguous relations. Hasan (1985) states that an ambiguous cohesive device is "one that could be interpreted in more than one way given the frame of the particular text" (ibid.: 89). In other words, an ambiguous cohesive relation occurs when the item can refer to two or more different items, which may result in confusion on the reader's part. The category of vagueness applies to reiteration pairs that are perceived as vague, i.e. are open to many possible interpretations. The next category gives information on the reiteration of informal or colloquial lexis, which is usually avoided in academic writing unless there is a clear intention or need for its use. Similarly, the next category concerns the cases of reiteration of pronouns $I, y o u$ and we that would be regarded as too personal (e.g. the use of pronoun you in general or the use of $I$ to express a personal opinion). The category of absence or redundancy applies to pairs where reiteration may be considered pointless (typically when the repeated item merely repeats the information already mentioned), or instances where an item should be naturally reiterated but is absent. The last two categories relate to the appropriate semantic choice of lexis and grammar accuracy. The examples of reiteration pairs identified in the pre- and post-tests that were evaluated as inappropriate/incorrect are given in the results section of the paper.

Due to its complexity, the analysis was conducted by a single rater. To increase intra-rater reliability, the procedure was applied twice, with a four-month interval between the first and second analysis. The results were computed separately for each student as a unit of analysis.

\section{Results and discussion}

Following the framework and analytical procedure suggested by Tanskanen (2006), a total of 3,131 reiteration pairs was identified. The total number of pairs of reiteration identified in the pre- and post-test corpora was nearly identical (1,514 as opposed to 1,617 pairs); a six per cent increase corresponds with a minor increase in the length of the post-tests.

\subsection{Research question 1}

As for the frequencies of the individual categories of reiteration, two types of reiteration relations were used less often in the post-test, namely simple repetition $(-7.4 \%)$ and substitution (-3.2\%). In the case of simple repetition, a paired t-test confirmed a statistically significant decline between both measures. The 
percentages for individual reiteration categories are given in Table 2. The decline in the use of simple repetition and corresponding increases in all remaining categories with the exception of substitution may be interpreted as a sign of discourse competence development and may be indicative of students' increased attention to the potential cases of clumsy repetition. Stotsky (1983) claims that "an increase in the use of morphologically complex words [i.e. complex repetition], rather than repetition of the same word or the use of a cumbersome paraphrase, may be an important index of growth" (as cited in Hoey 1991: 244). Hoey (1991: 243-244) makes the same observation, suggesting that one of the pedagogical implications for teaching the use of cohesive devices is encouraging the use of complex repetition to prevent clumsiness. Both claims refer to the use of complex repetition; nevertheless, similar observations could be made about other categories of reiteration, i.e. equivalence, generalisation, specification, co-specification and contrast, when used effectively. The above results may be attributed especially to the effect of the electronic feedback received as part of the composition of the two in-term writing assignments, and also to the input that was provided for autonomous interaction.

\begin{tabular}{|l|r|r|r|}
\hline Class of reiteration & Pre-test & Post-test & $\begin{array}{r}\text { Pre-/post-test } \\
\text { difference }\end{array}$ \\
\hline Simple repetition & $44.5 \%$ & $37.1 \%$ & -7.4 \\
\hline Complex repetition & $11.2 \%$ & $12.7 \%$ & +1.5 \\
\hline Substitution & $21.3 \%$ & $18.1 \%$ & -3.2 \\
\hline Equivalence & $7.3 \%$ & $9.5 \%$ & +2.2 \\
\hline Generalisation & $1.5 \%$ & $2.9 \%$ & +1.4 \\
\hline Specification & $4.1 \%$ & $5.1 \%$ & +1.0 \\
\hline Co-specification & $7.3 \%$ & $7.9 \%$ & +0.6 \\
\hline Contrast & $2.8 \%$ & $6.7 \%$ & +3.9 \\
\hline TOTAL & $100.0 \%$ & $100.0 \%$ & 0 \\
\hline
\end{tabular}

Table 2: Average relative frequencies of pairs of reiteration relations in the pre- and post-test

\subsection{Research question 2}

The second set of findings concerns the perceived (in)appropriateness/(in) correctness of the individual pairs of reiteration. A comparison of the pre-test and post-test corpora showed an average increase in pairs perceived as appropriate/ correct by 24.8 per cent (average relative frequencies are shown in Table 3 ). 
Reiteration Relations in EFL Student Academic Writing AND THE EFFECTS OF ONLINE LEARNING

\begin{tabular}{|l|r|r|r|r|}
\hline & & Pre-test & \multicolumn{2}{|r|}{ Post-test } \\
\hline Appropriate/Correct use & 1,001 & $66.1 \%$ & 1,417 & $90.9 \%$ \\
\hline Inappropriate/Incorrect use & 513 & $33.9 \%$ & 147 & $9.1 \%$ \\
\hline TOTAL & 1,514 & $100.0 \%$ & 1,617 & $100.0 \%$ \\
\hline
\end{tabular}

Table 3: Absolute and relative frequencies of (in)appropriate/(in)correct pairs of reiteration relations in the pre- and post-test

The paired t-test carried out at the level of individual students confirmed a statistically significant increase in the number of reiteration pairs that were classified as appropriate/correct. This result may be regarded as a sign of discourse competence development, suggesting that the participating students were able to achieve greater perceived fluency, stylistic appropriateness and lexical and grammar accuracy in their writing. The effect may be attributed to several factors, involving the emphasis placed on the writing process and its individual stages during the entire treatment, and the genre expectations related to the argumentative essay that were presented not only in the learning materials but also incorporated in the electronic guided feedback form for both teacherreview and peer-review.

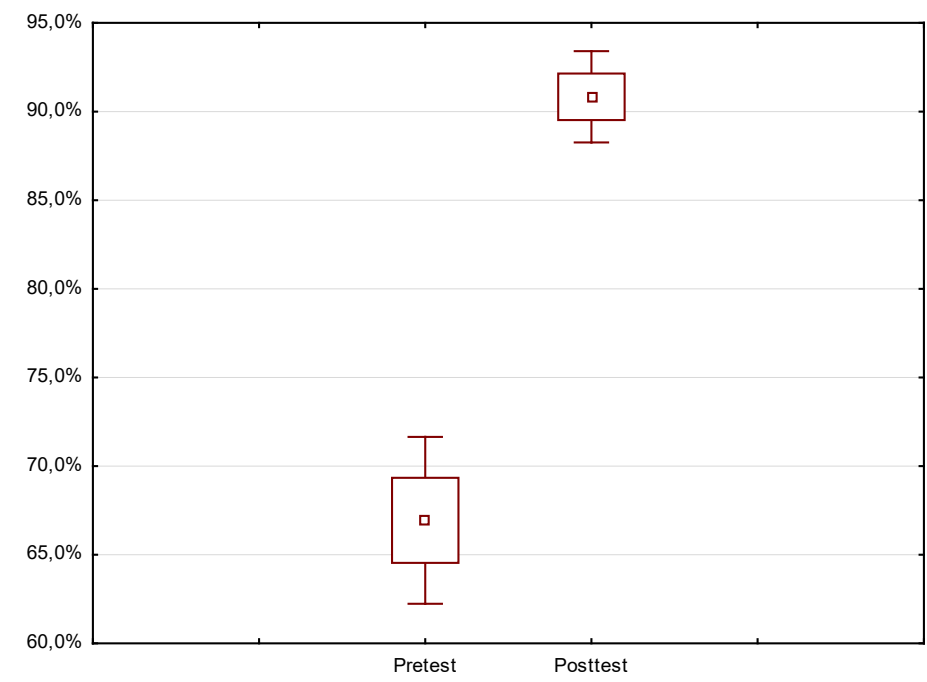

Graph 1: Results of the paired t-test for the share of appropriate/correct reiteration pairs before and after the treatment 
The data analysis showed that most cases of inappropriately/incorrectly used reiteration devices fell within three categories of reiteration relations, i.e. simple repetition (without pronouns), simple and complex pronoun repetition, and substitution. (It proved useful to treat pronoun repetition as a distinct class and establish the sub-classes of simple repetition - without pronouns, complex repetition - without pronouns, and pronoun repetition - both simple and complex. This modification helped to reveal some important specifics concerning the pronoun and non-pronoun repetition.) More specifically, the three categories accounted for 88.5 per cent of all inappropriate/incorrect pairs in the pre-test (out of 513 pairs) and for 85.0 per cent (out of 147 pairs) in the posttest. The remaining categories (complex repetition, equivalence, generalisation, specification, co-specification and contrast) lagged behind and therefore are not included in the further discussion.

The lower frequencies of inappropriate/incorrect pairs of reiteration were observed in all identified types of reiteration, with most notable declines in clumsy repetition, reiteration of items with inappropriate level of personality, reiteration of grammatically incorrect form(s) and perceived ambiguity (especially in pronoun use). The increase of appropriate/correct use and corresponding declines in the signs of immature writing are best seen when demonstrated for the individual categories of reiteration relations. Graphs 2, 3 and 4 below show differences between the pre-test and post-test results for the first three categories with the highest occurrence of inappropriate/incorrect signs, i.e. simple repetition (without pronouns), pronoun repetition (both simple and complex repetition) and substitution. The absolute frequencies of inappropriate/incorrect uses in the pretest corpus were 180, 152 and 120, and 42, 24 and 59 in the post-test corpus.
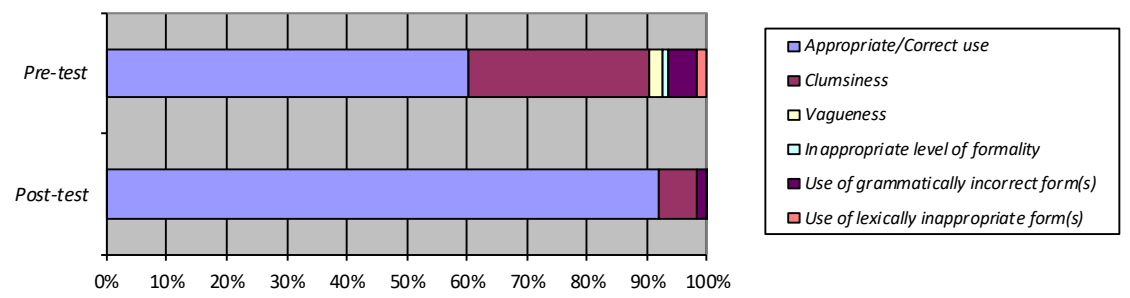

Graph 2: Average relative frequencies of (in)appropriate/(in)correct uses of simple repetition (without pronouns) in the pre- and post-test

As for simple repetition, the most notable average decline occurred in clumsiness (30.1\% compared to $6.1 \%)$ and in the use of grammatically incorrect 
form(s) (4.6\% compared to $1.6 \%)$. The other three types of inappropriateness/ incorrectness were generally very rare in the pre-tests and virtually non-existent in the post-tests. The examples of inappropriate/incorrect pairs of reiteration for the category of simple repetition are listed as Examples 1 to 5 below.

(1) Clumsiness: Secondly, many people describe the problem of poverty as a private government problem. The need of being involved in this problem is not considered as appropriate. (Student $\mathrm{H}$, post-test)

(2) Vagueness: Most of the things in universe try to find equilibrium or some kind of balance. Human body is the same case. It can adapt to many things e.g. to breathe with ... (Student B, pre-test)

(3) Inappropriate level of formality: Sometimes I face the situation that I have to divide kids into groups. [...] Then we can create several groups where the kids are of mixed gender. (Student K, pre-test)

(4) Use of grammatically incorrect form(s): Do we have some great source of informations or there is a need of more education and prevention in health area? [...] Everybody is finding informations about little health problems that they have. (Student H, pre-test)

(5) Use of lexically incorrect form(s): The preventist are these who can stop this way of living and help the people have the long, happy and healthy life without obesity. [...] In this case it is not important how loud the preventist shouting about the consequences of these foolish behaviour. (Student S, pre-test)

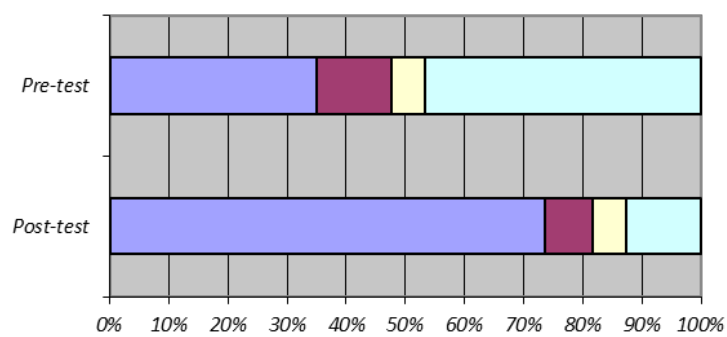

口Appropriate/Correct use

口Clumsiness

口Ambiguity

口Inappropriate level of personality

Graph 3: Average relative frequencies of (in)appropriate/(in)correct uses of pronoun repetition (both simple and complex) in the pre- and post-test

In terms of pronoun repetition, the average relative frequency of appropriate/ correct pairs of reiteration increased from $35.1 \%$ to $73.6 \%$. Graf 3 shows that this improvement occurred mainly because of the decline in the use of pronoun forms with inappropriate level of personality (46.8\% compared to $12.6 \%$ ). In the pre-test (and to a lesser extent in the post-test too), first person pronouns 
were frequently used in the body of the argumentative essay, where the writer is supposed to discuss supporting arguments and achieve the expected level of objectivity. The use of first person pronouns ( $I$, and is some cases we) needs to be done with caution as claims that are perceived as too personal negatively impact on the perceived persuasiveness. As regards clumsiness, a five-percent improvement between the pre- and post-test was observed, while the average frequency of ambiguous pairs remained constant (around 5.5\%). The examples of inappropriate/incorrect pairs of reiteration for the category of pronoun repetition follow.

(6) Clumsiness: According to some research, only 5\% people in Britain exercise regularly. Then they are ill, suffering from heart or bone problems, they need to visit different kinds of doctors and pay an enormous amount of money for pills, which are making them suffer from side effects. If they have just lived a different, healthier kind of life, such a thing would not occur. (Student N, pre-test)

(7) Ambiguity: Such individuals seem to believe that a pain-killer pill is able to cure their health problem for good. However, the pills they regularly take are only able to reduce and relieve their pain. (Student F, pre-test)

(8) Inappropriate level of personality: If you suffer from genetically caused illness for example, there is mostly nothing you can do about it. (Student E, pre-test)
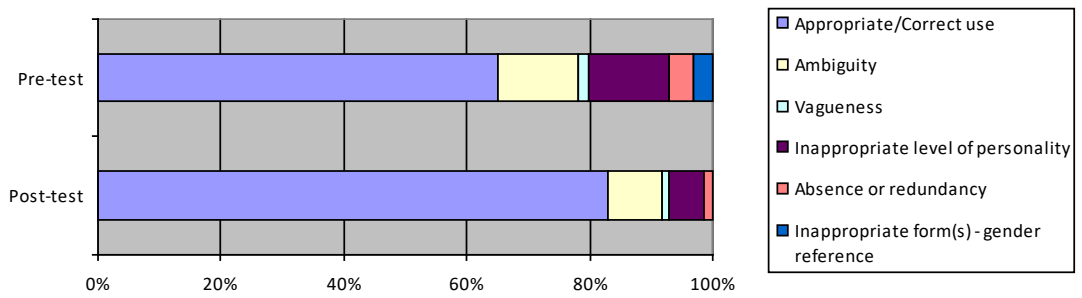

Graph 4: Average relative frequencies of (in)appropriate/(in)correct uses of substitution in the pre- and post-test

Graph 4 illustrates the results for the category of substitution. The problems identified in the pre-test included ambiguous and vague pronoun usage, inappropriate level of personality (pronoun forms you and we), absent or redundant items, and also the use of less appropriate forms for gender reference (as in Example 13), specifically reference to a single gender where a reference involving both genders might be considered more appropriate. The examples of problematic substitution relations are included as items (9-13) below. 
The post-test scores for the individual signs of immature writing were generally lower, with a most notable decline in the inappropriate level of personality (12.9 vs. $5.7 \%)$ and ambiguity $(12.9$ vs. $8.9 \%)$. After the treatment, no inappropriate gender reference was identified.

(9) Ambiguity: We can't push anybody to stop smoking, it is legal, but on the other hand, a society as a whole will be paying his healthcare when he gets cancer. (Student R, pre-test)

(10) Vagueness: Nowadays in some countries they started to prevent obesity. (Student $\mathrm{U}$, pre-test)

(11) Inappropriate level of personality: Nowadays many people suffer from different illnesses, even from those, that are really easy to prevent. If you suffer from genetically caused illness for example, there is mostly nothing you can do about it. (Student E, pre-test)

(12) Absence or redundancy: Therefore doing even more research $\underline{\text { t }}$ would cause even bigger mess, rendering this approach not productive at all. (Student Z, pre-test)

(13) Inappropriate form(s) for referring to gender: ... a person goes through the city centre with the idea of lovely meal for lunch, he founds nothing but fastfoods. (Student G, pre-test)

\subsection{Research question 3}

The third research question addressed the potential change in the length of lexical chains formed by key lexical units in the pre-test and post-tests. For each pre-test and post-test topic, seven key lexical units covering the respective thematic scope were chosen and their occurrence was monitored. The paired t-test (cf. Graph 5) confirmed a statistically significant increase in the number of reiteration pairs formed by these seven lexical units at the level of individual students, and thus also a statistically significant difference in the length of lexical chains contributing to a text's thematic progression. This finding may be regarded as a very important sign of development because it signals that after the treatment, the participating students were able to achieve a greater thematic unity throughout their compositions. The development of this aspect of discourse competence may be attributed to the effect of the provided input as well as to the use of guided feedback form containing criteria that specifically addressed the thematic progression and relevance of ideas presented in the individual parts of the in-term writing assignments. 


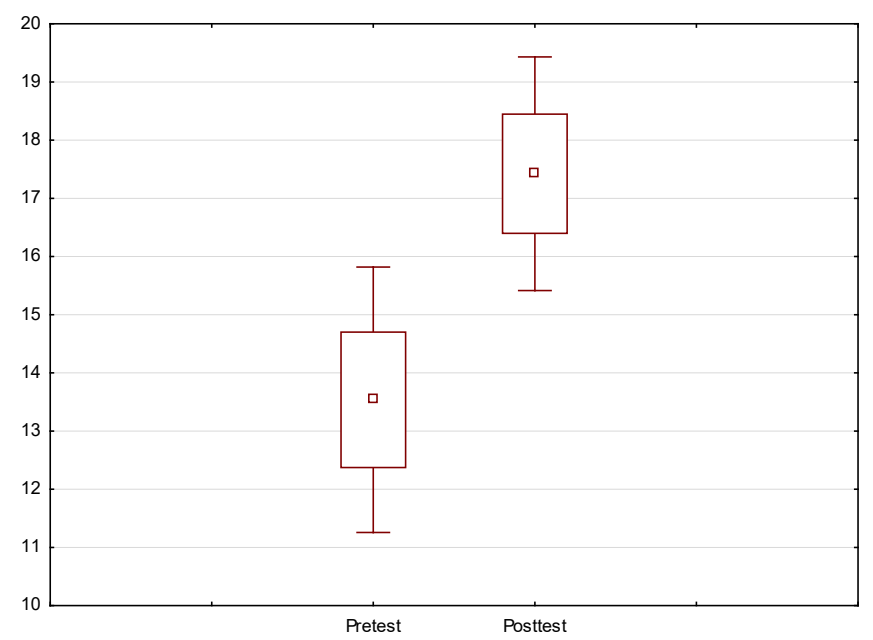

Graph 5: Absolute frequencies of the key lexical units forming lexical chains contributing to a text's thematic progression in the pre- and post-test

\section{Conclusion}

The context information obtained by means of questionnaires administered before and after the intervention confirmed the potential influence of extraneous variables; however, their effect was found to be rather limited. Therefore, it may be concluded that the development of the three aspects of discourse competence that were in the centre of attention of this empirical study may be mostly attributed to the effects of the treatment. Based on the above findings, it may be claimed that the experimental treatment carried out in the Masaryk University Learning Management System and the Peer-Review Application resulted in a more effective use of lexical cohesion (subclass of reiteration) in the participating students' EFL writing. After the treatment, a greater variety of reiteration relations was identified, with declines in simple repetition and corresponding increases in the remaining categories of reiteration relations (with the exception of substitution). The decline in the use of simple repetition may be indicative of students' increased awareness of the other types of reiteration relations as well as their conscious effort to prevent formation of clumsy (monotonous) relations. As regards the second research question, the pre-/post-test comparison showed a statistically significant increase in the number of reiteration pairs that were classified as appropriate/correct. The most significant declines in categories of inappropriate/incorrect use were observed in terms of clumsiness, ambiguity and inappropriate level of personality. Finally, longer chains of cohesion contributing 
to a greater thematic progression were identified in the post-tests. It may be concluded that after the intervention, the participating students were able to form reiteration relations that attracted less negative attention on the part of the reader, and their compositions were perceived as more mature.

\section{Limitations}

This study clearly has its limitations, the first being the quasi-experimental research design. Although the potential influence of extraneous variables was to a large extent minimized, it must be admitted that some of the external factors might be responsible for part of the perceived development. The second major limitation results from the challenge of identification and evaluation of reiteration relations in learners' (mostly B2) inter-language, which is a rather demanding task. Finally, it needs to be admitted that the evaluation of appropriateness/ inappropriateness of the individual pairs of reiteration is prone to a certain level of subjectivity.

Despite its limitations, the study gives a valuable insight into the effects of autonomous online learning on the development of lexical cohesion, namely the class of reiteration. It appears that providing learning opportunities of a similar type may be an effective way of foreign language instruction, in particular when there is a clear motivation and specific learning goals on students' part as was the case in this study.

\section{References}

Bachman, L. F. and Palmer, A. S. (1996) Language Testing in Practice: Designing and Developing Useful Language Tests. Oxford: Oxford University Press.

Badger, R. and White, G. (2000) 'A process genre approach to teaching writing.' ELT Journal 54/2, 153-160.

Brown, G. and Yule, G. (1983) Discourse Analysis. Cambridge: Cambridge University Press.

Canale, M. (1983) 'From communicative competence to communicative language pedagogy.' In: Richards, J. and Schmidt, R. (eds) Language and Communication. London: Longman. 2-27.

Celce-Murcia, M. (2007) 'Rethinking the role of communicative competence.' In: Alcón Soler, E. and Safont Jordà, M. P. (eds) Intercultural Language Use and Language Learning. Dordrecht: Springer. 41-57.

Cohen, M., Manion, L. and Morrison, K. (2011) Research Methods in Education. London: Routledge.

De Beugrande, R. and Dressler, W. U. (1981) Introduction to Text Linguistics. London: Longman.

Dontcheva-Navratilova, O. (2012) 'Coherence and cohesion in research articles: The role of indexicals.' In: Dontcheva-Navratilova, O., Jančaříková, R., Miššíková, G. and Povolná, R. (eds) Coherence and Cohesion in English Discourse. Brno: Masarykova univerzita, Pedagogická fakulta. 9-28. 
Gall, M. D., Gall, J. P. and Borg, W. R. (2010) Applying Educational Research: How to Read, Do, and Use Research to Solve Problems of Practice. Boston: Pearson.

Halliday, M. A. K. and Hasan, R. (1976) Cohesion in English. Harlow: Longman.

Hasan, R. (1984) 'Coherence and cohesive harmony.' In: Flood, J. (ed.) Understanding Reading Comprehension. Delaware: International Reading Association. 181-219.

Hasan, R. (1985) 'The texture of a text.' In: Halliday, M. A. K and Hasan, R. Language, Context, and Text: Aspects of Language in a Social-Semiotic Perspective. Oxford: Oxford University Press. 70-96.

Hoey, M. (1991) Patterns of Lexis in Text. Oxford University Press: Oxford.

Hoey, M. (2001) Textual interaction: An Introduction to Written Discourse Analysis. London and New York: Routledge.

Kumaravadivelu, B. (2006) Understanding Language Teaching: From Method to Postmethod. Mahwah, NJ: Lawrence Erlbaum Associates Publishers.

Larsen-Freeman, D. and Anderson, M. (2011) Techniques and Principles in Language Teaching. Oxford: Oxford University Press.

Linell, P. (1998) Approaching Dialogue: Talk. Interaction and Contexts in Dialogical Perspectives. Amsterdam and Philadelphia: John Benjamins.

Martin, J. R. (1992) English Text: System and Structure. Amsterdam and Philadelphia: John Benjamins.

Morris, J. and Hirst, G. (1991) 'Lexical cohesion computed by thesaural relations as an indicator of the structure of text.' Computational Linguistics 17, 21-48.

Savignon, S. J. (1983) Communicative Competence: Theory and Classroom Practice. Reading, MA: Addison-Wesley.

Savignon, S. (1997) Communicative Competence: Theory and Classroom Practice: Texts and Contexts in Second Language Learning. New York: McGraw-Hill.

Stotsky, S. (1983) 'Types of lexical cohesion in expository writing: Implications for developing the vocabulary of academic discourse.' College Composition and Writing, 34/4, 430-445.

Swain, M. (1985) 'Communicative competence: Some roles of comprehensible input and comprehensible output in its development.' In: Gass, S. and Madden, C. (eds) Input in Second Language Acquisition. Rowley, MA: Newbury House. 235-253.

Swain, M. (2005) 'The output hypothesis: Theory and research.' In: Hinkel, E. (ed.) Handbook of Research in Second Language Teaching and Learning. New York: Routledge. 471-483.

Tanskanen, S.-K. (2006) Collaborating towards Coherence: Lexical Cohesion in English Discourse. Amsterdam: John Benjamins Publishing.

Usó-Juan, E. and Martínez-Flor, A. (2006) Current Trends in the Development and Teaching of the Four Language Skills. Berlin: M. de Gruyter.

Gabriela Hublová is Assistant Professor at the Language Centre of Masaryk University, Brno, Czech Republic. Her dissertation dealt with the effects of autonomous online learning on the development of discourse competence in EFL student academic writing. The selected aspects of discourse competence included text structure and organisation, and grammatical and lexical cohesion.

Address: Mgr. Gabriela Hublová, Ph.D., Language Centre, Faculty of Education Unit, Masaryk University, Poříčí 7, 60300 Brno, Czech Republic. [e-mail: hublova@ped.muni.cz] 